\title{
An analysis of the cloud environment over the Ross Sea and Ross Ice Shelf using CloudSat/CALIPSO satellite observations: the importance of synoptic forcing
}

\author{
Ben Jolly $^{1}$, Peter Kuma ${ }^{2}$, Adrian McDonald ${ }^{2}$, and Simon Parsons ${ }^{2}$ \\ ${ }^{1}$ Landcare Research, Lincoln, New Zealand \\ ${ }^{2}$ Department of Physics and Astronomy, University of Canterbury, Christchurch, New Zealand
}

Correspondence: Ben Jolly (jollyb@landcareresearch.co.nz)

Received: 13 June 2017 - Discussion started: 7 August 2017

Revised: 15 April 2018 - Accepted: 1 May 2018 - Published: 10 July 2018

\begin{abstract}
We use the 2B-GEOPROF-LIDAR R04 (2BGL4) and R05 (2BGL5) products and the 2B-CLDCLASS-LIDAR R04 (2BCL4) product, all generated by combining CloudSat radar and CALIPSO lidar satellite measurements with auxiliary data, to examine the vertical distribution of cloud occurrence around the Ross Ice Shelf (RIS) and Ross Sea region. We find that the 2BGL4 product, used in previous studies in this region, displays a discontinuity at $8.2 \mathrm{~km}$ which is not observable in the other products. This artefact appears to correspond to a change in the horizontal and vertical resolution of the CALIPSO dataset used above this level. We then use the $2 \mathrm{BCL} 4$ product to examine the vertical distribution of cloud occurrence, phase, and type over the RIS and Ross Sea. In particular we examine how synoptic conditions in the region, derived using a previously developed synoptic classification, impact the cloud environment and the contrasting response in the two regions. We observe large differences between the cloud occurrence as a function of altitude for synoptic regimes relative to those for seasonal variations. A stronger variation in the occurrence of clear skies and multi-layer cloud and in all cloud type occurrences over both the Ross Sea and RIS is associated more with synoptic type than seasonal composites. In addition, anomalies from the mean joint histogram of cloud top height against thickness display significant differences over the Ross Sea and RIS sectors as a function of synoptic regime, but are near identical over these two regions when a seasonal analysis is completed. However, the frequency of particular phases of cloud, notably mixed phase and water, is much more strongly modulated by seasonal than synoptic regime compositing,
\end{abstract}

which suggests that temperature is still the most important control on cloud phase in the region.

\section{Introduction}

Antarctic tropospheric clouds have been the subject of many studies, including relevant reviews by Lachlan-Cope (2010) and Bromwich et al. (2012). Detailed ground or airborne observation campaigns (e.g. Scott and Lubin, 2014, 2016) are difficult, expensive to conduct and rare in this region (Lachlan-Cope, 2010); however, satellite measurements have made a number of useful insights possible (Verlinden et al., 2011; Bromwich et al., 2012; Adhikari et al., 2012). The properties of snow- and ice-covered ground - namely being white, highly reflective, and very cold - pose challenges to the use of passive satellite sensors for cloud identification (Frey et al., 2008). These challenges are largely circumvented by the active instruments on the CloudSat (Stephens et al., 2008) and CALIPSO (Winker et al., 2009) satellites whose data we use in this study. While detailed atmospheric models potentially allow further studies over far greater regional and temporal scales (Fogt and Bromwich, 2008; Nicolas and Bromwich, 2011; Steinhoff et al., 2009), cloud is difficult to model and accurately forecast, particularly over Antarctica and the Southern Ocean (Bromwich et al., 2012), with the paucity of observations a contributing factor.

The Antarctic coastal region is one of the most active areas of synoptic-scale cyclonic storms in the Southern Hemisphere (Hoskins and Hodges, 2005), with Adhikari et al. 
(2012) suggesting that these lows are associated with deep and high-level clouds and precipitation. Additionally, Tsukernik and Lynch (2013) identified that the meridional moisture flux is dominated by motions at synoptic scales and reveal that the Amundsen Sea sector experiences the highest variability around the Antarctic, a potential driver of the variability observed in the region. This study focuses on cloud properties over the Ross Sea and the Ross Ice Shelf (RIS) because these regions are of particular interest in understanding the controls of cloud properties around Antarctica. For example, it has been reported that the largest seasonal variations in cloud occurrence across the Antarctic are observed in these regions, with close to $60 \%$ during winter and $90 \%$ in the summer (Adhikari et al., 2012). A number of recent studies (Scott and Lubin, 2014, 2016) have also identified unique cloud properties in these regions, and case studies detailed in Scott and Lubin (2014) suggest a strong dependence on the meteorological scenario.

The RIS is a largely flat expanse of permanent ice fed by both the West Antarctic Ice Sheet (WAIS) and East Antarctic Ice Sheet (EAIS). The western edge of the shelf is bounded by the $2 \mathrm{~km}$ high barrier of the Transantarctic Mountains (TAM), with the EAIS behind. The surface meteorology of the region is dominated by katabatic winds from the ice sheets (Parish and Bromwich, 1991, 2007), and low-pressure systems over the Ross Sea. The Ross Sea is located along the northern boundary of the RIS and frequently experiences large low-pressure systems originating off the coast of Adélie Land located well to the north-west. These are known to advect moist marine air from the ocean/sea ice onto the RIS, often via the WAIS and Siple Coast (Nicolas and Bromwich, 2011). Nicolas and Bromwich (2011) also highlighted the importance of marine air intrusions for cloud fraction over the West Antarctic Ice Sheet driven by cyclonic activity in the Ross and western Amundsen seas. This combination of cyclones, the barrier presented by the TAM, and katabatic drainage helps to feed a southerly wind regime that dominates the climatology of the RIS known as the Ross Ice Shelf airstream (RAS) (Parish et al., 2006). Steinhoff et al. (2009) discussed a case study where a cyclone off Marie Byrd Land transported moisture across the WAIS to the southern base of the RIS which formed into cloud due to both low-level convergence and lifting caused by a "knob flow". A distinct extended thermal infrared signature hypothesized to be associated with low-level cloud was observed along the corridor of high winds linked to this RAS event. Recent work by Coggins et al. (2014) has developed a synoptic classification scheme by applying the $k$-means clustering method to 33 years of ERA-Interim surface wind data. This has been useful in understanding the range, frequency, and influence of the different phenomena around the RIS (see Sect. 2.2 for details). More recent work by Coggins and McDonald (2015) demonstrated how the position and depth of the Amundsen Sea Low influences the frequency and form of these different weather regimes over the Ross Sea and RIS. This study aims to quantify cloud occurrence over the RIS and southern Ross Sea using the CloudSat/CALIPSO 2B-CLDCLASS-LIDAR product (Sassen et al., 2008), both spatially and vertically. We also examine the occurrence, phase, and type of cloud with a focus on whether synoptic drivers, identified via the synoptic regimes developed by Coggins et al. (2014), provide a coherent pattern.

Clouds over the Southern Ocean and Antarctica can consist of liquid water, mixed phases (i.e. consisting of supercooled liquid water droplets and ice crystals), or ice crystals (Haynes et al., 2011; Chubb et al., 2013; Scott and Lubin, 2014; Lawson and Gettelman, 2014). Cloud phase is important to determine because ice crystals and water droplets have different radiative properties and therefore reflect and absorb different levels of incoming shortwave radiation (Haynes et al., 2011; Scott and Lubin, 2014). Cloud composition over Antarctica and the Southern Ocean is currently not well understood or modelled; however, Lawson and Gettelman (2014) have shown that the radiative budget in this area is highly sensitive to changes in cloud phase.

Chen et al. (2000) have shown that different types of clouds have distinctive microphysical properties, resulting in different radiative forcings (Chen et al., 2000; Tselioudis et al., 2013; Oreopoulos et al., 2016; McDonald et al., 2016). It is therefore clear that classification is an important task. The International Satellite Cloud Climatology Project (ISCCP) uses passive measurements to classify clouds into nine different types based on their cloud top pressure and cloud optical thickness (Rossow and Schiffer, 1999). Later work by Wang and Sassen (2001) developed an approach to classify clouds into eight types by combining radiometer observations with "active" measurements from groundbased lidar and radar. This classification scheme was modified for CloudSat and CALIPSO observations to provide cloud type distributions globally which are available in the 2B-CLDCLASS-LIDAR R04 (2BCL4) product used in this study (Sassen et al., 2008; Wang et al., 2012).

A recent study by Scott and Lubin (2014) investigated clouds over McMurdo station, located at the north-western corner of the RIS, using spectroradiometer measurements as well as observations from the NASA A-Train satellites. They identified two major sources of moisture: marine air intrusions originating over the WAIS which then cross the RIS (predominantly ice-based), and moist air advection from the Ross Sea (more likely to contain liquid). Large cyclones in the Ross Sea did not contribute significant levels of moisture at Ross Island. In a follow-up study, Scott and Lubin (2016) extended this work to show a link between high ice content and increased vertical motion of the air parcel prior to observation.

Verlinden et al. (2011) used vertical profiles of cloud occurrence from a pre-R05 2B-GEOPROF-LIDAR product (Mace et al., 2009; Mace and Zhang, 2014). They found a pronounced seasonal cycle in cloudiness over Antarctica and the Southern Ocean with higher cloud occurrences dur- 
ing the winter. They also found a nearly discontinuous dropoff in cloudiness near $8 \mathrm{~km}$ over much of the continent. However, they and the review by Bromwich et al. (2012) have questioned whether this is an artefact in the data because this discontinuity corresponds to a change in the horizontal and vertical resolutions of the CALIPSO data. Verlinden et al. (2011) also highlighted that their vertical profiles revealed two distinct maxima, with one near the surface level and the other near the top of the troposphere.

The increase in cloud during winter is contrary to the findings of Adhikari et al. (2012), who calculated seasonal variations spatially and found that summer and autumn featured higher cloud occurrence than winter and spring over most of Antarctica and the Southern Ocean, but particularly over the RIS. Sea ice was suggested as a contributing factor, blocking evaporation that occurs over open water, along with the extremely low temperatures. Low-level cloud featured the highest inter-seasonal variability, with low occurrence during winter and reduced occurrence during spring relative to summer and autumn. Haynes et al. (2011) also examined clouds over the Southern Ocean using a combination of active and passive satellite data. They separated the clouds in this region into eight regimes, but identified that all of these regimes contained a relatively high occurrence of low cloud, with $79 \%$ of all cloud layers observed featuring tops below $3 \mathrm{~km}$ in altitude. Multi-layered cloud systems were observed in approximately $34 \%$ of cloud profiles. Haynes et al. (2011) also found that cloud systems are geometrically thicker during the austral winter and that all of the eight regimes show enhanced low-level cloud fraction in the summer but that the seasonal variation at higher levels is more complex. Those regimes found to be most closely associated with mid-latitude cyclones also produced precipitation more frequently.

\section{Datasets and methods}

\subsection{CloudSat/CALIPSO data}

CloudSat (Stephens et al., 2008) and CALIPSO (Winker et al., 2009) are two satellites that exist within the NASA A-Train, a constellation of satellites with identical orbits that pass over the same parts of the earth within a narrow time window (less than $1 \mathrm{~km}$ apart $90 \%$ for the time period used in this study (Mace and Zhang, 2014). CloudSat carries a millimetre-wavelength $(94 \mathrm{GHz})$ cloud profiling radar (CPR) with a vertical resolution of $240 \mathrm{~m}$ and a sea-level footprint of $1.4 \mathrm{~km} \times 1.7 \mathrm{~km}$. It detects tiny water droplets within clouds while also penetrating through optically dense upper layers to detect further layers at lower altitudes; however, studies have shown that it struggles to resolve cloud below $1 \mathrm{~km}$ above ground level due to ground clutter (Mace et al., 2009). The Cloud-Aerosol Lidar with Orthogonal Polarization (CALIOP) instrument carried by the CALIPSO satellite provides vertical resolution of the order of 30 to $60 \mathrm{~m}$ with a roughly circular sea-level footprint of $100 \mathrm{~m}$ in diameter. It is able to accurately detect cloud down to ground level, but has reduced sensitivity during daylight operations and cannot penetrate thick cloud. In particular, this study uses the 2B-GEOPROF-LIDAR R04 (2BGL4) and R05 (2BGL5) products (Mace et al., 2009; Mace and Zhang, 2014) which combine the CALIOP and CPR observations to examine the vertical distribution of cloud occurrence. We also use the $2 \mathrm{BCL} 4$ product which provides cloud occurrence, phase, and cloud type information using a combination of CPR, CALIOP, and MODIS output with ancillary temperature information from the European Centre for Medium-Range Weather Forecasts (ECMWF). Analysis presented in Sect. 3 shows that the pre-R04 2B-GEOPROFLIDAR products (Verlinden et al., 2011; Adhikari et al., 2012; Bromwich et al., 2012, amongst others) display a discontinuity at $8.2 \mathrm{~km}$ which appears to be limited to the poles in both regions. Mace et al. (2009) indicates that the CALIOP data have a centre-to-centre pacing of $333 \mathrm{~m}$ between profiles in the horizontal and a $30 \mathrm{~m}$ vertical resolution below $8.2 \mathrm{~km}$. Above $8.2 \mathrm{~km}$, further averaging is applied to create a $1 \mathrm{~km}$ along-track resolution and a $60 \mathrm{~m}$ resolution in the vertical. Thus, we believe that the observed discontinuity is related to this change. We therefore focus our analysis on the use of the 2BCL4 product.

The 2BCL4 product classifies clouds by examining the vertical profiles and horizontal extent of clouds derived from the CPR and CALIOP measurements, the presence of precipitation, cloud temperature from ancillary ECMWF predictions, and upward radiances from MODIS measurements (Wang et al., 2012) and is consistent with the previous ISCCP classification (Rossow and Schiffer, 1999). The clustering algorithm uses a combination of rule-based and fuzzy logic classification schemes to achieve this end. The cloud types identified by the 2BCL4 product and their main defining characteristics are identified in Table 1. Factors taken into account in the classifier include cloud top and base height and temperature, as well as cloud phase, thickness, horizontal extent and cover. Different thresholds for cloud top/base heights are chosen for polar regions, tropics, and mid-latitudes. Reported cloud phase is restricted by cloud base and cloud top temperature. For cloud base temperature below $-38.5^{\circ} \mathrm{C}$, only ice cloud is permitted. For cloud base temperature between -38.5 and $1{ }^{\circ} \mathrm{C}$, all phases are permitted (liquid, ice and mixed). For cloud base temperature above $1{ }^{\circ} \mathrm{C}$, the cloud is classified as liquid when cloud top temperature is above $-7^{\circ} \mathrm{C}$, liquid or mixed when the cloud top temperature is between -38.5 and $-7^{\circ} \mathrm{C}$ or mixed for cloud top temperature below $-38.5^{\circ} \mathrm{C}$ (Wang et al., 2012). Although CALIOP provides the depolarization ratio to identify cloud phase, it is not reliable alone due to multiple scattering and the fact that the CALIOP signal is quickly attenuated in multi-layer and thick clouds. Instead, it is used in combination with the attenuated backscatter coefficient and radar reflectivity, and exploits differences in the number concentra- 


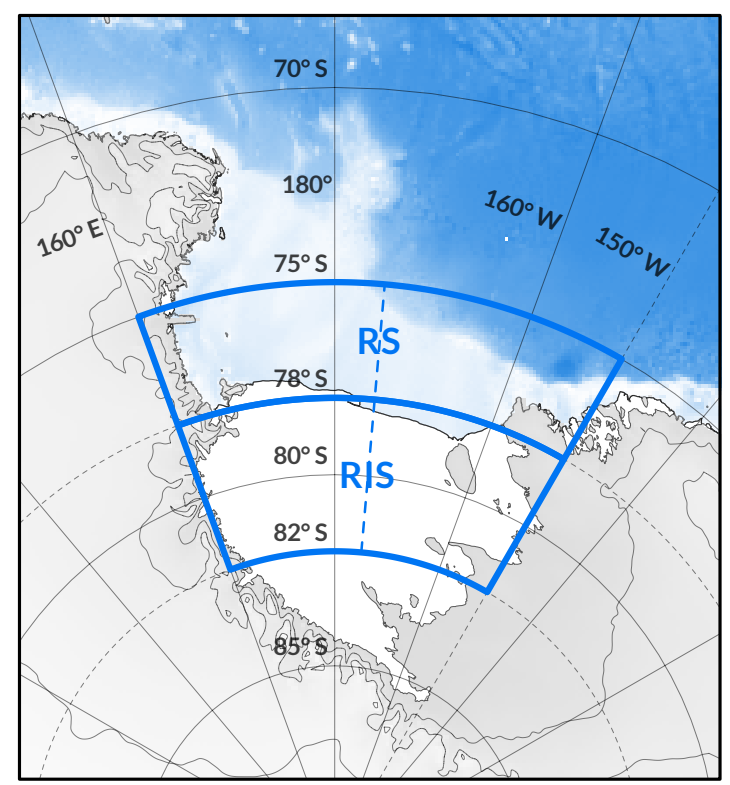

Figure 1. Topographic map of the RIS and Ross Sea including the boundaries of the study area (thick blue line) and border between the RIS and Ross Sea sectors. (Map derived from the SCAR Antarctic Digital Database.)

tion, vertical distribution, and radiative properties of ice particles and water droplets to distinguish different phase clouds when this cannot be uniquely determined by cloud top/base temperature alone. In this study, the stratus (St) and stratocumulus (Sc) cloud types have been agglomerated based on advice released on the CloudSat website (CloudSat Data Processing Center, 2016).

The area of interest in this study covers as much of the RIS as possible and extends into the southern Ross Sea. Defined by the edges of the ice shelf $\left(160\right.$ to $\left.-150^{\circ} \mathrm{E}\right)$, it extends from the bottom of the A-Train track at $82^{\circ} \mathrm{S}$ north to $75^{\circ} \mathrm{S}$. The area is divided into two sectors (RIS and the Ross Sea) along the $78^{\circ} \mathrm{S}$ circle of latitude, each of which are further divided into east/west sectors to form four quadrants. Figure 1 identifies the study region and its bounds. Note that despite the larger area of the Ross Sea compared to the RIS defined in this study, the number of vertical profiles linked to the RIS region is far higher than that for the Ross Sea (4.1 vs. 1.8 million). This disparity is associated with a strong latitudinal variation in the sampling density associated with the satellite orbits. This study uses observations made between 1 January 2007 and 31 December 2010 when both the CloudSat and CALIPSO satellites were fully operational and aligned.

In Sect. 3 we inspect cloud occurrence as a function of altitude for different cloud phases and the cloud fraction. The cloud occurrence is derived by counting the occurrence of cloud at a particular altitude using the CloudLayerBase and CloudLayerTop fields of the 2BCL4 product. This is in contrast to the methodology used in Verlinden et al. (2011), which used a threshold of $50 \%$ for the CloudFraction field (fraction of lidar volumes in a radar resolution volume that contains hydrometeors) for determination of cloud occurrence. In this study we calculate the cloud fraction (not related to the CloudFraction field) as the complement of the clear sky fraction, which is the number of clear sky profiles divided by the total number of profiles. As such, it is independent of altitude.

\subsection{Synoptic climatology}

To provide context on atmospheric circulation over the duration of this study, classifications and regimes developed in the work of Coggins et al. (2014) and Coggins and McDonald (2015) are used. Five broad synoptic-scale regimes, hereafter referred to as "Coggins regimes", encompass 20 classes created by applying the $k$ means clustering technique to $10 \mathrm{~m}$ winds from 33 years of ERA-Interim reanalysis (Dee et al., 2011) over the RIS/Ross Sea region. The 20 classes grouped into five regimes were found to be representative of conditions in the area and span the entire time period of available cloud observations, and so are an obvious choice for this analysis. The first two Coggins regimes are the weak northern cyclonic (WNC) and strong northern cyclonic (SNC) regimes which feature cyclones to the north of the RIS, with the "weak" and "strong" ratings referring to their effect on the winds over the RIS; WNC generally provides weak forcing and low wind speeds, while SNC features a strong synoptic pressure gradient force and high wind speeds over the RIS. The Ross Ice Shelf airstream (RAS) Coggins regime covers the strongest winds over the RIS and typically features a strong cyclone to the north and east that provides a large pressure gradient over the ice shelf which forms RAS-like signatures (Parish et al., 2006), while the weak southern cyclonic (WSC) regime is associated with relatively weak cyclones and mesocyclones positioned over the RIS with medium wind speeds. Finally, the weak synoptic (WS) Coggins regime covers periods where a very weak pressure gradient and very low winds are present over the RIS.

Table 2 shows the relative frequency of occurrence of the regimes over the entire observational period examined and a normalized seasonal frequency. Examination of the "all" column shows that the WSC regime is relatively rare (9\% annual frequency), while the WS regime is observed frequently (29\%). The WNC and RAS regimes are also quite common ( 25 and $23 \%$ respectively), while SNC is less common $(14 \%)$. Seasonal analysis of the frequency of occurrence shows the WNC regime occurs most frequently during austral autumn (34\%) but much less frequently during winter (19\%), while the SNC regime is more uniform across all four seasons - this likely reflects the ubiquitous nature of synoptic-scale cyclonic storms around Antarctica (Hoskins and Hodges, 2005). The RAS regime is seen much more fre- 
Table 1. Cloud types identified by the 2BCL4 cloud classification algorithm and some of the properties upon which the algorithm is based. Abbreviations: cloud base (CB), horizontal extent (HE), vertical extent (VE), liquid water content (LWP). Adapted from Table 3 in Wang et al. (2012).

\begin{tabular}{llllrl}
\hline Cloud type & CB $(\mathrm{km})$ & HE $(\mathrm{km})$ & VE $(\mathrm{km})$ & $\mathrm{LWP}\left(\mathrm{kg} \mathrm{m}^{-2}\right)$ & Rain \\
\hline High cloud (Ci) & $7-$ & $1-1000$ & $1-7$ & $=0$ & none \\
Altostratus (As) & $2-7$ & 1000 & $1-7$ & $\approx 0$ & none \\
Altocumulus (Ac) & $2-7$ & 1000 & $0-7$ & $>0$ & virga possible \\
Stratus (St) & $0-2$ & 100 & $0-1$ & $>0$ & none or slight \\
Stratocumulus (Sc) & $0-2$ & 1000 & $0-1$ & $>0$ & drizzle or snow possible \\
Cumulus (Cu) & $0-3$ & $1-$ & $0-7$ & $>0$ & drizzle or snow possible \\
Deep convective (DC) & $0-3$ & $10-$ & $7-$ & $>0$ & intense shower of rain or hail possible \\
Nimbostratus (Ns) & $0-4$ & $50-1000$ & $7-$ & $>0$ & prolonged rain or snow \\
\hline
\end{tabular}

Table 2. Relative frequency of occurrence of the Coggins regimes annually (all) and seasonally (DJF-SON) in the ERA-Interim reanalysis (\%). DJF/MAM/JJA/SON correspond to austral summer/autumn/winter/spring respectively. Values for seasons are normalized so that rows sum to $100 \%$ (not including "all").

\begin{tabular}{lrrrrr}
\hline & all & DJF & MAM & JJA & SON \\
\hline WNC & 23 & 24 & 34 & 19 & 23 \\
SNC & 14 & 22 & 27 & 26 & 25 \\
RAS & 25 & 10 & 28 & 37 & 25 \\
WSC & 9 & 12 & 36 & 30 & 23 \\
WS & 29 & 36 & 17 & 21 & 27 \\
\hline
\end{tabular}

quently in winter (37\%) than summer (10\%), while the WSC and WS regimes alternately favour autumn (WSC $36 \%$ ) and summer (WS $36 \%$ ) at the expense of summer (WSC 12\%) and autumn (WS 17\%). It must be noted that Table 2 is structured for seasonal analysis of individual regimes (rows sum to $100 \%$ ) and does not provide a comparable statistic of regime frequency in each season (season columns do not sum to $100 \%)$.

\section{Results}

\subsection{Discontinuity in the 2B-GEOPROF-LIDAR R04 product}

As an initial point of comparison with the previous Antarcticwide studies of Verlinden et al. (2011) and Adhikari et al. (2012) we display seasonal mean cloud occurrence statistics in Fig. 2 derived from the 2BGL4, 2BGL5 and 2BCL4 products for the Ross Sea and the RIS. A visual comparison between the three products generally shows good agreement (within a few percentage points), though the 2BGL4 values of cloud occurrence are a little above the values derived from the other two products everywhere below $8 \mathrm{~km}$. A step change in the cloud occurrence can also be observed at $8.2 \mathrm{~km}$ in all seasons and over both the Ross Sea and the
RIS in the 2BGL4 product. It should be noted that this step change is particularly large in the winter and spring and is also significantly larger over the RIS than the Ross Sea. The 2BGL5 and 2BCL4 values do not display this discontinuity and are much more similar to each other, though it is noticeable that the 2BCL4 values of cloud occurrence are always smaller than the other two products below $1 \mathrm{~km}$. Interestingly the temporal average cloud occurrence for the 2BGL4 product is always larger than that for the 2BCL4 product, which in turn is always greater than the 2BGL5 product.

To further examine the extent of this issue, Fig. 3 displays the zonal mean value of the ratio of the cloud occurrence at $8.3 \mathrm{~km}$ to the cloud occurrence at $8.0 \mathrm{~km}$ derived from the three products. The two altitude bins are in consecutive height bins, but are linked to different vertical and horizontal resolutions in the 2BGL4 processing scheme according to Mace et al. (2009). Inspection of Fig. 3 shows that the ratio varies between 0.9 and 1.1 for all three products near the Equator and at mid-latitudes. However, the 2BGL4 value of the ratio deviates significantly from that derived from the other two products at latitudes poleward of $75^{\circ}$ in both hemispheres. The deviation between the 2 BGL5 product and the 2BCL4 product is also relatively large in the Northern Hemisphere above $60^{\circ} \mathrm{N}$. Previous studies (Verlinden et al., 2011; Bromwich et al., 2012; Adhikari et al., 2012) have highlighted this discontinuity near $8 \mathrm{~km}$, but have questioned whether it is an instrumental artefact or a physical feature. The analysis in Fig. 3 clearly suggests that this is an instrumental artefact specific to both polar regions. The larger discontinuity observed in Fig. 2 in winter may suggest a temperature-dependent issue. But, further analysis is beyond the scope of this study given the good correspondence between the 2BCL4 and 2BGL5 products.

\subsection{Cloud occurrence and phase by season}

Given the uncertainty identified within the 2BGL4 (GEOPROF) product, we choose to deviate from previous studies and use the 2BCL4 (CLD-CLASS) product. We consider this preferable to the $2 \mathrm{BGL} 5$ product, despite the apparent reso- 

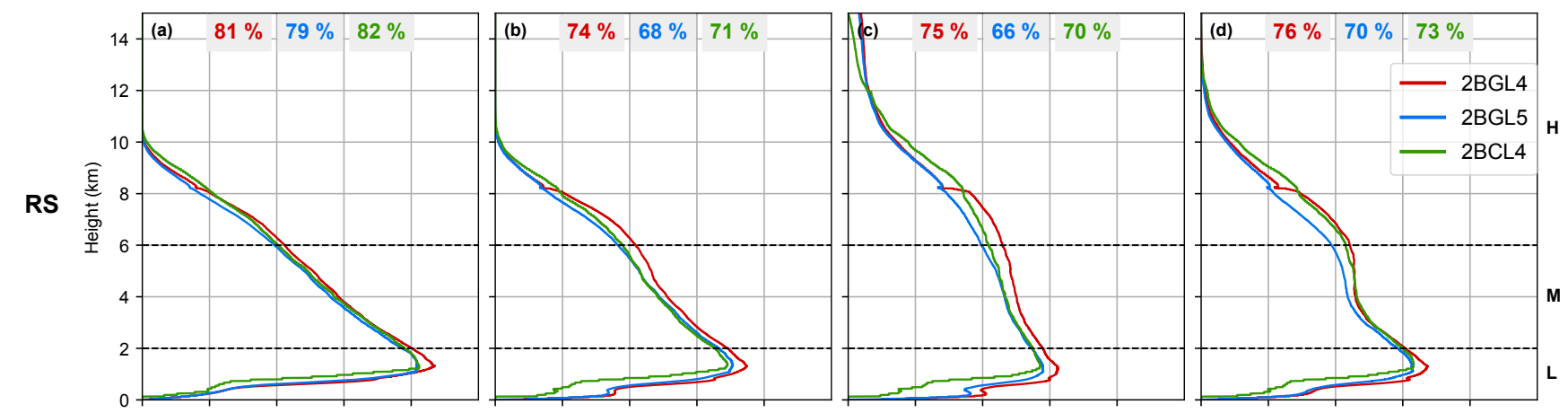

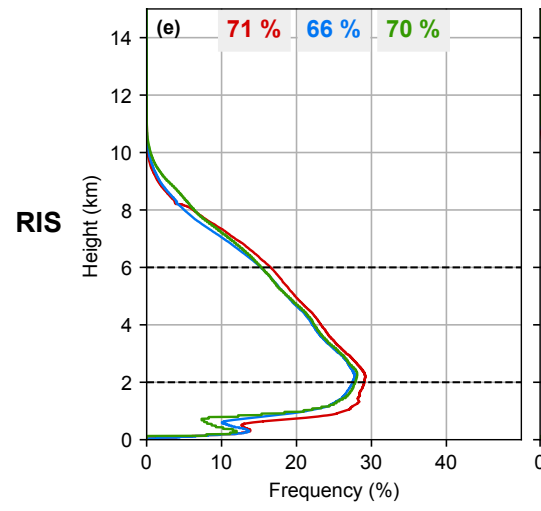

DJF

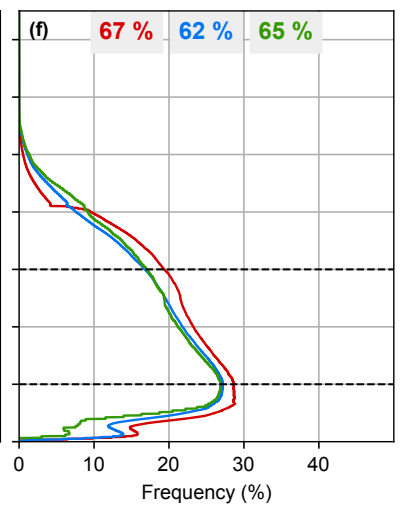

MAM

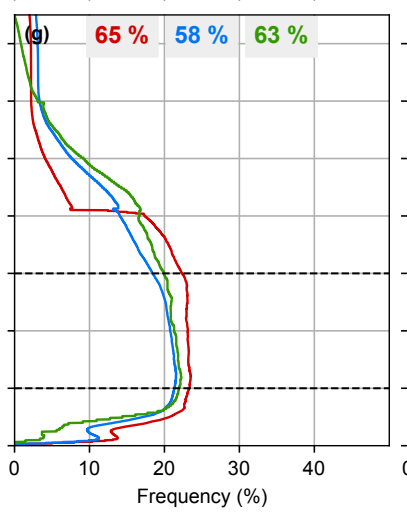

JJA

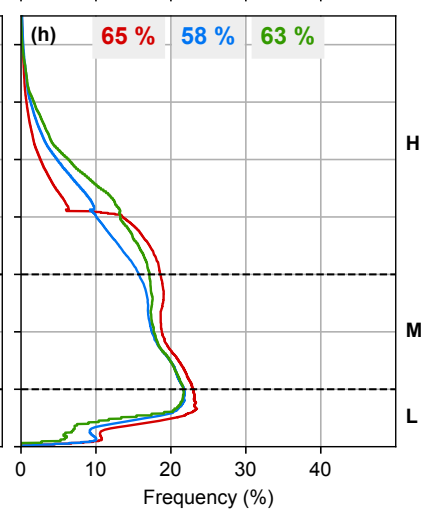

SON

Figure 2. Mean vertical profiles of cloud occurrence derived from the 2BGL4, 2BGL5 and 2BCL4 data for the Ross Sea (a-d) and RIS sectors (e-h) for different seasons. Total sector cloud fraction (temporal average cloud occurrence independent of altitude) is annotated at the top of each sub-figure. L, M, and H labels indicate the low, medium, and high cloud regions, respectively, as discussed in the text.

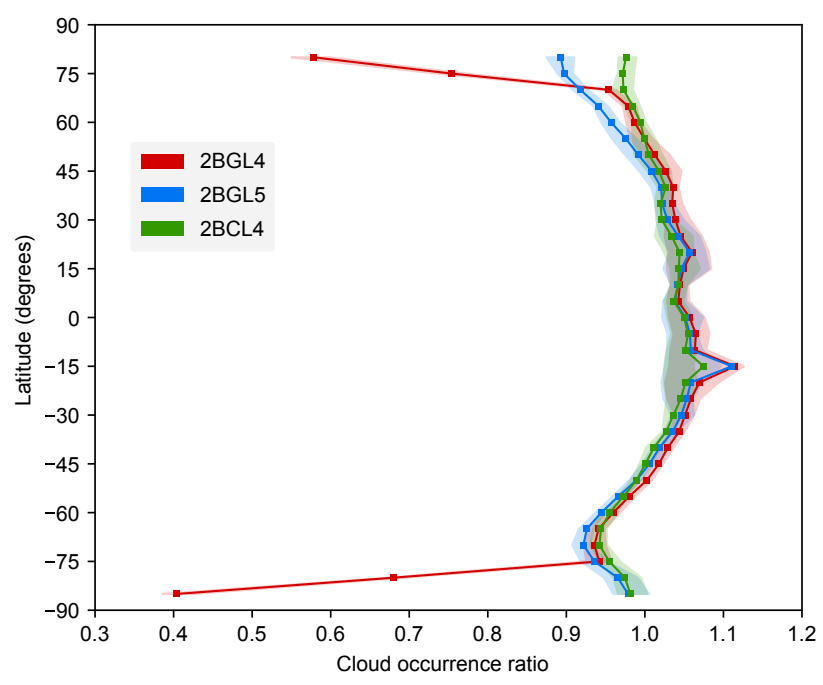

Figure 3. Latitudinal variation of the ratio of cloud occurrence at $8.3 \mathrm{~km}$ to cloud occurrence at $8.0 \mathrm{~km}$ derived from the 2B-GEOPROF-LIDAR products and the 2B-CLDCLASS-LIDAR products. The envelopes represent the interquartile ranges of the ratio observed at that latitude. Note that consistently anomalous values $\ll 1$ are confined to the polar latitudes. lution of the uncertainties in 2BGL4, as it provides information on cloud phase and type, which are particularly interesting in this region. We initially examine cloud occurrence as a function of cloud phase. Adhikari et al. (2012) reported that the largest seasonal variations in cloud occurrence were observed over the RIS and sea ice region in the surrounding Ross Sea, suggesting this region may be of particular interest in understanding the controls of cloud in the region. Cloud occurrence is separated into two sectors: the Ross Sea and the RIS (see Fig. 1). For the purpose of this analysis we separate clouds into three vertical ranges: low-level clouds $(0-2 \mathrm{~km})$, mid-level clouds $(2-6 \mathrm{~km})$ and high-level clouds $(6-\mathrm{km})$ identified by horizontal lines in Figs. 2, 4 and 5.

Figure 4a-d display the cloud occurrence for the Ross Sea region in each season broken into different cloud phases (shaded areas). The maximum cloud fraction ( $82 \%$ ) is observed during summer, with the minimum cloud fraction $(70 \%)$ observed during winter. The largest cloud fraction is observed over the eastern portion of the Ross Sea in every season, with the greatest seasonal cloud fraction in summer $(86 \%)$. The smallest cloud fraction $(66 \%)$ was observed in winter over the western portion of the Ross Sea. Cloud occurrence as a function of altitude shows the same pattern, with the maximum (about $40 \%$ ) occurring in summer and the minimum (about $27 \%$ ) during winter. Though all max- 

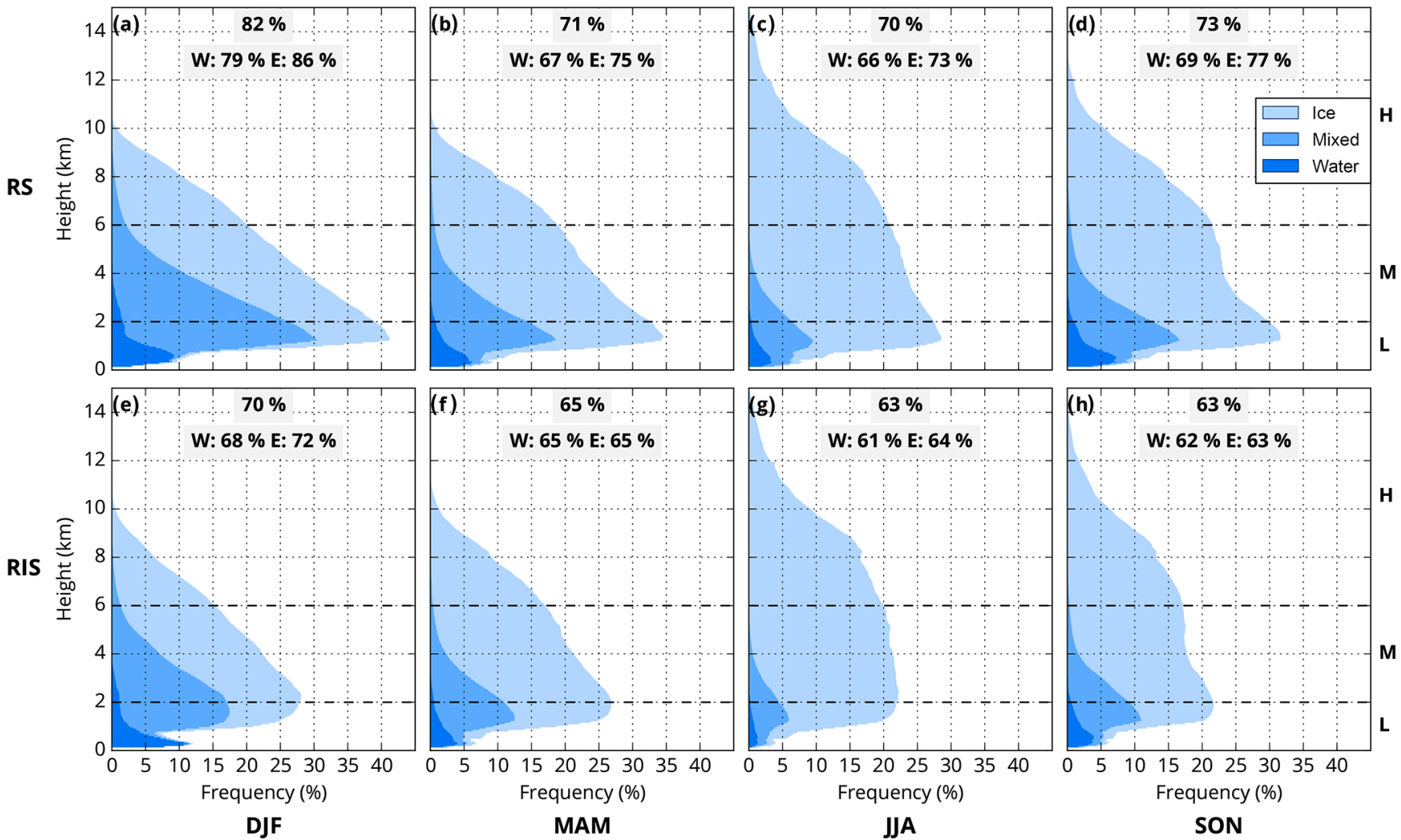

Figure 4. Mean vertical profiles of cumulative cloud occurrence for different cloud phases derived from 2BCL4 data for the Ross Sea (ad) and RIS sectors (e-h) for different seasons. Total sector cloud fraction (temporal average cloud occurrence independent of altitude) is annotated at the top of each sub-figure, along with values for the western (W) and eastern (E) halves of each sector. L, M, and $\mathrm{H}$ labels indicate the low, medium, and high cloud regions, respectively, as discussed in the text.

ima occur between 1.5 and $2 \mathrm{~km}$ above sea level (a.s.l.), the winter maximum is noticeably weaker. Mixed phase clouds are predominant near the cloud occurrence altitudinal maximum, with water and ice cloud contributing roughly equally to the remainder. Changes in the occurrence of mixed phase cloud appear to constitute the majority of the change in the cloud occurrence at that altitude.

Cloud occurrence reduces uniformly at increasing altitude from the maxima in summer and autumn, while in winter the cloud occurrence reduces rapidly between the peak and $3.5 \mathrm{~km}$ a.s.l., and then remains relatively uniform before a more rapid reduction at higher altitudes $(8 \mathrm{~km}$ in winter and $6 \mathrm{~km}$ in spring). Previous work detailed in Verlinden et al. (2011) highlighted a discontinuity in cloudiness near $8 \mathrm{kma}$ as.l. over much of the continent which appears to be linked to the processing artefact identified previously.

Unlike the study of Verlinden et al. (2011) we do not observe two distinct maxima in the vertical profiles of the cloud occurrence; however, this feature was relatively weak over the WAIS (see Fig. 5 in Verlinden et al., 2011), which may hint at the specific drivers of the cloud environment in this region. In particular, the absence of a secondary peak in mid- and high-level cloud occurrence is interesting given the ubiquitous nature of cyclones in the region (Hoskins and Hodges, 2005), and the muted seasonal signal in cloud occurrence above $2 \mathrm{kma}$ a.s.l. could be explained by the lack of a strong seasonal signal in cyclone frequency in this region (supported by the small seasonal signal in the frequency of the SNC regime displayed in Table 2). The difference in our cloud occurrence calculation methodology to that used by Verlinden et al. (2011) may have some impact; however, it is unlikely to explain all of the difference.

As might be expected, the liquid water phase occurs predominantly in low-level clouds with a local maximum between 300 and 900 ma.s.l. in all seasons, the largest enhancement occurring during summer. The difficulty of detecting cloud within $1 \mathrm{~km}$ of the ground using CloudSat due to ground clutter (Mace et al., 2009; Haynes et al., 2011) may bias low-level cloud detection in favour of periods of reduced attenuation of the CALIOP lidar instrument (clear sky or optically thin mid- to high-level cloud). Mid-level (between 2 and $6 \mathrm{~km}$ a.s.1.) cloud occurrence varies little between seasons at the upper limit $(6 \mathrm{~km})$ at close to $20 \%$, but mid-level cloud fraction is greatest in summer and lowest in winter. More high-level cloud (above $8 \mathrm{~km}$ a.s.l.) is observed during winter than summer, which matches with the results identi- 
fied in Adhikari et al. (2012). We also note that clouds were not observed in this study above $10 \mathrm{~km}$ a.s.l. in both the summer and autumn, or $12 \mathrm{~km}$ in spring, but were seen above $14 \mathrm{~km}$ in the winter. Haynes et al. (2011) suggest that the maximum cloud height over the Southern Ocean will be impacted by the seasonal variations in tropopause depth likely explains this pattern, which interestingly shows a similar seasonal progression to that for polar stratospheric cloud occurrence (Alexander et al., 2011, 2013).

The mean seasonal cloud occurrence vertical profiles for the RIS are displayed in Fig. 4e-h. The eastern portion of the RIS has slightly greater cloud occurrence than the western portion of the RIS in all seasons apart from autumn. The cloud fraction for the RIS area is $70 \%$ in summer and between 63 and $65 \%$ in all other seasons. The greatest cloud fraction by sector is observed over the eastern RIS during summer (72\%), while the lowest is observed in winter over the western RIS (61\%). Inspection of the cloud occurrence as a function of altitude shows a maximum at approximately $2 \mathrm{~km}$ a.s.l. in every season, slightly higher than the altitude of the peak observed over the Ross Sea. This peak in cloud occurrence matches with a similar peak in ice water content (IWC) and liquid water content (LWC) values discussed in Scott and Lubin (2016) over Ross Island (located at the south-western corner of the Ross Sea region in this study). Summer experiences the greatest cloud occurrence as a function of altitude at this peak, but the seasonal variability is rather muted (just under 5\% variation across all seasons) relative to that observed over the Ross Sea (approximately $12 \%$ ), with the minimum in winter. The mixed phase class is a contributor to this peak in all seasons, but is dominant in summer. The cloud occurrence linked to the ice phase is slightly larger than that for mixed phase cloud in autumn.

Again, the water phase occurs predominantly for low-level clouds (below $2 \mathrm{kma.s.1}$.) with maxima below $600 \mathrm{~m}$ observed in every season (this is particularly clear for summer). The ice phase is effectively the only contributor for highlevel clouds (above $6 \mathrm{~km}$ ) and is the largest contributor to cloud occurrence in every season, though mixed phase cloud is dominant up to approximately $3 \mathrm{~km}$ in summer. The quantity of mixed and water phase cloud as a proportion of total cloud occurrence is substantially lower than that observed over the Ross Sea, possibly suggesting a lack of moisture in this region and the impact of colder temperatures.

The seasonal variation in cloud occurrence at mid-levels (between 2 and $6 \mathrm{~km}$ a.s.1.) is approximately $5-10 \%$, which is smaller than the variations observed at the peak occurrence level. Within this altitude range, cloud occurrence is more constant in winter and spring and reduces with altitude in spring and summer. The cumulative occurrence of mid-level clouds is marginally higher in summer than other seasons, with a minimum value in winter. High-level clouds (above $6 \mathrm{~km}$ ) are distinctly more common in autumn and winter than spring and summer. Similar to the Ross Sea case, the majority of clouds are limited to below $10 \mathrm{~km}$ a.s.l. in both the summer and autumn, with maximum high-cloud occurrence in winter. Over the entire vertical profile, the seasonal variation over the RIS is smaller than that observed over the Ross Sea (cf. Fig. 4a-d and e-h).

\subsection{Cloud occurrence and phase by synoptic regime}

We now examine composites of the vertical distribution of cloud occurrence and cloud fraction for these two regions based on the synoptic-scale Coggins regimes. Figure 5a-e display the cloud occurrence profiles over the Ross Sea for the five different Coggins regimes. Comparison of Fig. 5a-e shows that the combined cloud occurrence (associated with the three different cloud phase classes) in every regime again maximizes just below $2 \mathrm{~km}$ a.s.l. The greatest occurrence at that peak is observed in the SNC regime and the smallest occurrence in the WSC regime. At middle altitudes (4 to $6 \mathrm{~km}$ ), the difference in cloud occurrence between regimes is very large, with the SNC regime again displaying the largest cloud occurrences (between 28 and $35 \%$ in this altitude range) and the WSC regime the least (between 7 and 17\%). The WSC and WS regimes have rather similar vertical profiles, with the vast majority of cloud occurrence linked to low- to mid-level clouds below $4 \mathrm{kma}$.s.l. The SNC type on the other hand has high cloud occurrence at nearly all levels compared to the other regimes and has signs of a secondary maximum at $5 \mathrm{~km}$. The RAS and WNC have intermediate levels of cloud occurrence between the SNC and WSC/WS regimes, with shallower rates of reduction in the cloud occurrence above the peak.

Inspection of the distribution of phases linked to the SNC regime (linked to strong cyclonic activity in the north of the Ross Sea) suggests that this regime is dominated by ice cloud at all levels down to about $2 \mathrm{~km}$ a.s.l. (i.e. mid- to high-level clouds are predominately comprised of ice). A small amount of water phase cloud is observed very close to the surface and a peak in mixed phase cloud is observed just below the peak in the combined cloud occurrence. The quantity of mixed phase cloud being larger than the ice phase only occurs in the WS and WNC types near the low-level maxima. The SNC and RAS regimes feature the largest proportion of ice cloud overall. The cloud fraction (see labels in Fig. 5) varies from $82 \%$ for the SNC regime to $58 \%$ for the WSC regime, with the other regimes having values between 72 and $77 \%$. This variation is significantly larger than that observed when observations are composited based on season. This result suggests that cloud fraction is strongly impacted by synoptic situation. In particular, the SNC regime has high occurrence frequencies in the mid- to high-level cloud region above $2 \mathrm{~km}$ a.s.l. Additionally, we note that the variation between the western and eastern portions of the Ross Sea is larger in the SNC, RAS, and WSC regimes (10-13\%) than over the seasons (7-8\%), while the WNC regime shows little variation longitudinally. This suggests that synoptic forcing is a more important control on longitudinal differences than 
season, though this should be expected because the strength and position of cyclonic centres is a principal determinant of the Coggins regimes. While overall the synoptic typing seems to be important, we note that the proportion of liquid and mixed phase cloud varies relatively little over the Ross Sea as a function of the Coggins regimes (between approximately 15 and $20 \%$ at the altitude of maximum occurrence), while the seasonal variation is substantially larger (between approximately 9 and $30 \%$ at the altitude of maximum occurrence). This result supports the view that temperature is a strong driver of the occurrence of ice cloud as previously identified by Haynes et al. (2011), though the variability observed between synoptic types suggests that temperature anomalies associated with specific synoptic types also have some influence.

Figure $5 \mathrm{f}-\mathrm{j}$ display composites for the RIS for the Coggins regimes. Cloud occurrence is significantly smaller in every regime relative to the profiles over the Ross Sea (cf. Fig. 5a-e). Examination of the cloud occurrence profiles as a function of altitude for each regime suggests that the WNC, WSC, and WS regimes have similar forms, as do the SNC and RAS regimes (to each other). Interestingly, cloud occurrence is higher in the RAS regime between 2 and $6 \mathrm{~km}$ than SNC. This likely suggests that the impact of cyclones in the northern Ross Sea is not as strong an influence on cloud over the RIS. At mid to high levels (above $4 \mathrm{~km}$ ), RAS and the SNC have the largest cloud occurrences, with ice cloud dominating in this region. The variation at upper levels is also noticeably larger between the various synoptic regimes in Fig. 5 than between the seasons displayed in Fig. 4. This seems to suggest that the synoptic state is a stronger driver of mid- to high-level cloud than seasonal variations, this being particularly clear when we consider that the regime with most high-level cloud (the SNC regime) displays almost no seasonality (see Table 2). Figure 5 therefore shows an advantage in using a classification scheme based on synoptic states relative to one using seasons in this region. Previous work by Haynes et al. (2011) also suggested that seasonality might not be a strong influence on the Southern Ocean, with two exceptions, these being the quantity of ice cloud and the height at which the maximum cloud fraction occurs in the upper troposphere.

Examination of the cloud fraction over the entire RIS and the western and eastern sectors shows less variability than over the Ross Sea. The cloud fraction varies only between 55 and $68 \%$ and the differences in cloud fraction between the western and eastern sectors are only sizeable $(9 \%)$ for the WSC regime. The difference between the cloud fraction between the western and eastern sectors is $5 \%$ or less in all other regimes. Given that the WNC and SNC regimes are dominated by the positions of cyclones over the Ross Sea, this may not be surprising in those cases. However, the lack of longitudinal variation associated with the RAS which is traditionally linked to flow near the TAM is a surprise.

\subsection{Multilayer cloud by season and regime}

While useful, the mean vertical profiles of cloud occurrence displayed in Figs. 4 and 5 do not fully represent the individual profiles composited in that season or regime. For example, two states associated with a distinct high and low cloud type might be combined in the averaging process to form the mean cloud occurrence observed. Alternatively, multilayered cloud might be present and contribute to the mean cloud occurrence profiles. In an effort to display this variability, Fig. 6 shows the quantity of clear skies, single-layer cloud, and multi-layer cloud for the Coggins regimes and seasons over the Ross Sea and RIS. Inspection of Fig. 6a for the Ross Sea region suggests that clear skies are observed $26 \%$ of the time on average. However, when the cloud occurrence information is composited based on the Coggins regime, the frequency of occurrence of clear skies varies between $18 \%$ for the SNC regime and $42 \%$ for the WSC regime. Seasonal variations in clear sky occurrence are considerably smaller at 18 to $30 \%$. Again, this highlights that clouds are observed preferentially in the Ross Sea when strong cyclonic centres are observed in the northern Ross Sea. Changes in the frequency of multi-layer clouds are also notable, with the frequency varying from $15 \%$ for the WSC regime to $33 \%$ for the SNC regime. The occurrence of multilayer cloud is considerably more constant as a function of season, varying between 21 and $25 \%$, which highlights that the quantity of multi-layer cloud is also strongly impacted by synoptic conditions.

Figure $6 \mathrm{~b}$ displays the occurrence of clear skies, singlelayer cloud and multi-layer cloud for the RIS region. The variability as a function of both Coggins regime and season is again muted relative to the Ross Sea region. The occurrence of clear skies varies from $32 \%$ for the SNC regime to $45 \%$ for WSC, with the other three regimes having frequencies between 34 and $35 \%$, which is similar to that for the SNC regime. This suggests that only the synoptic conditions linked to the WSC regime are strongly linked to clear skies. When clear sky occurrence is examined as a function of season, a very small seasonal variability is observed (values fall between 30 and $37 \%$ ). This reinforces our previous conclusion for the Ross Sea region: that clear skies are not strongly influenced by season and therefore surface temperatures. Examination of multi-layer cloud values shows a variation between $15 \%$ for WSC and $23 \%$ for both the RAS and SNC types. This suggests that the RAS regime is also preferentially related to multi-layer cloud over the RIS. Work by Steinhoff et al. (2009) has previously suggested that the RAS regime might be linked to the occurrence of low- and midlevel cloud, the latter being associated with vertical ascent generated by low-level convergence as the RAS decelerates downstream of wind speed maximum along the TAM. This relationship also appears to be observed based on our statistical analysis. The high occurrence of cloud at mid-levels (between 2 and 6 kma.s.l.) displayed in Fig. $2 \mathrm{~g}$ therefore sug- 

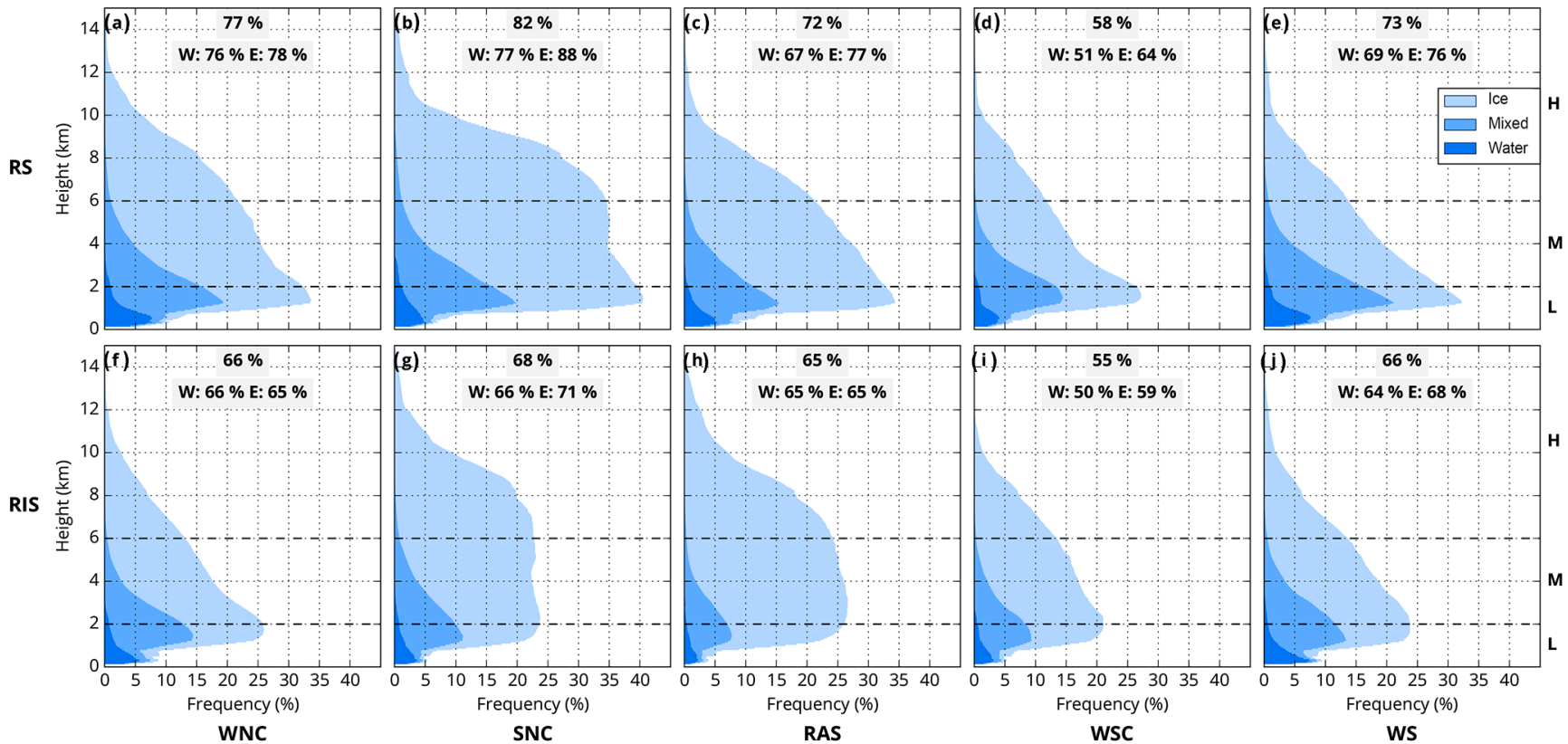

Figure 5. Mean vertical profiles of cumulative cloud occurrence for different cloud phases derived from 2BCL4 data for the Ross Sea (a-e) and RIS regions (f-j) for the Coggins regimes. L, M, and $\mathrm{H}$ labels indicate the low, medium, and high cloud regions, respectively, as discussed in the text.

gests that the RAS and possibly the marine air intrusions identified in Nicolas and Bromwich (2011) have a noticeable climatological impact on cloud occurrence over the RIS. In addition, the seasonal progression and variation linked to synoptic typing display very different impacts over the Ross Sea and RIS. This perhaps highlights the stronger influence of cyclones on cloud occurrence over the Ross Sea than the RIS. The higher frequency of occurrence of multi-layer cloud linked to the SNC type over the Ross Sea than the RIS also suggests the position of the cyclone centre plays an important role in cloud distributions.

\subsection{Cloud type by season and regime}

Figure 7 displays the fractional occurrence of the various cloud types over the Ross Sea and RIS composited based on Coggins regime and season. For the sake of conciseness, we will only discuss the types which have substantial fractional occurrence rates (above $15 \%$ in any class). The frequency of nimbostratus $(\mathrm{Nb})$ is so small over these regions that this type is not included in Fig. 7. For the Ross Sea, the most commonly occurring cloud type is deep convective (DC), which varies from $32 \%$ for the WS regime to $43 \%$ for the RAS regime, with the other regimes ranging between 32 and $39 \%$ (see Fig. 6a). This cloud type is likely identified due to large horizontal and vertical extents of the cloud rather than the presence of deep convection in the polar region. The seasonal variation has a maximum in autumn of $42 \%$ with a minimum of $36 \%$ in winter. Thus, in this high-level cloud type, more variation between classes is associated with synoptic classification than season. Interestingly the maximum occurrence of this type over the Ross Sea is associated with the RAS regime rather than the SNC regime, previously identified as the regime associated with the highest cloud occurrence. When we additionally include the impact of clear skies (values displayed in Fig. 6), this conclusion remains unchanged.

The next most common cloud type over the Ross Sea is the altostratus (As) type, which varies between 30 and $36 \%$ based on Coggins regimes and between 29 and $36 \%$ based on season. In particular, the fractional occurrence of this cloud type maximizes in winter and minimizes in summer over the Ross Sea. However, when the frequency of clear skies (see Fig. 6) is also considered, the seasonal variation becomes very small ( 23 to $25 \%$ ), while the regime variation is enhanced to 17 to $30 \%$. Thus, in this case close inspection also suggests that synoptic forcing is a driver of the occurrence of this cloud type, with the highest occurrence in the SNC regime and lowest occurrence in the WSC regime. Note that the As type is predominantly a mid- to high-level cloud dominated by ice and thus may not be strongly impacted by seasonally varying quantities, such as sea ice cover and surface temperature.

Low-level clouds (combined stratus/stratocumulus or $\mathrm{St} / \mathrm{Sc}$ types) are observed relatively frequently in the WS $(21 \%)$ and WSC (19\%) regimes over the Ross Sea. Both these regimes are associated with weaker synoptic forcing and observed less frequently than the regimes with stronger synoptic forcing. Seasonal variation in these types changes 
(a)

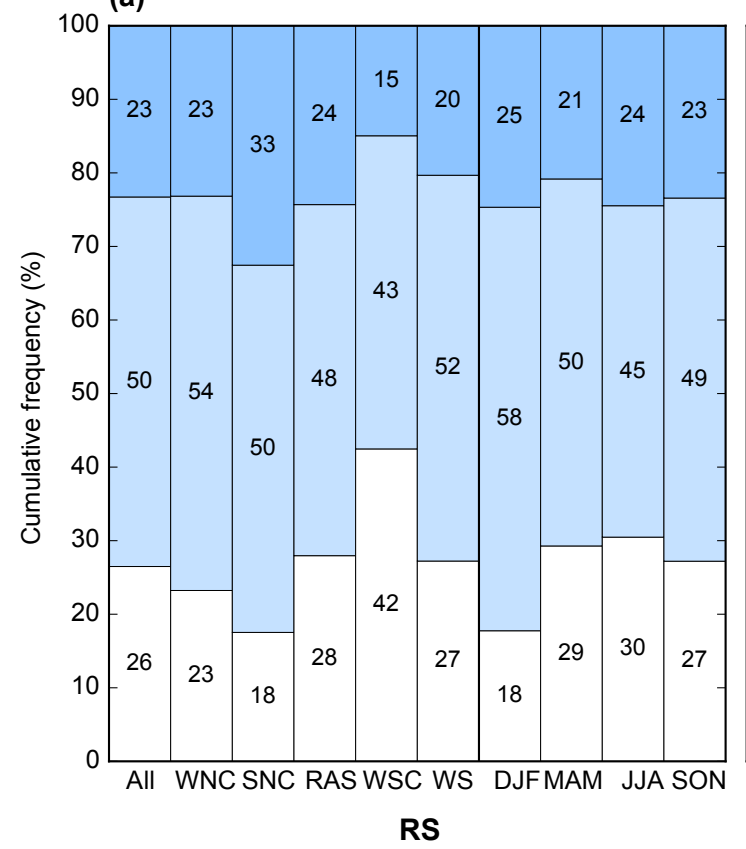

(b)

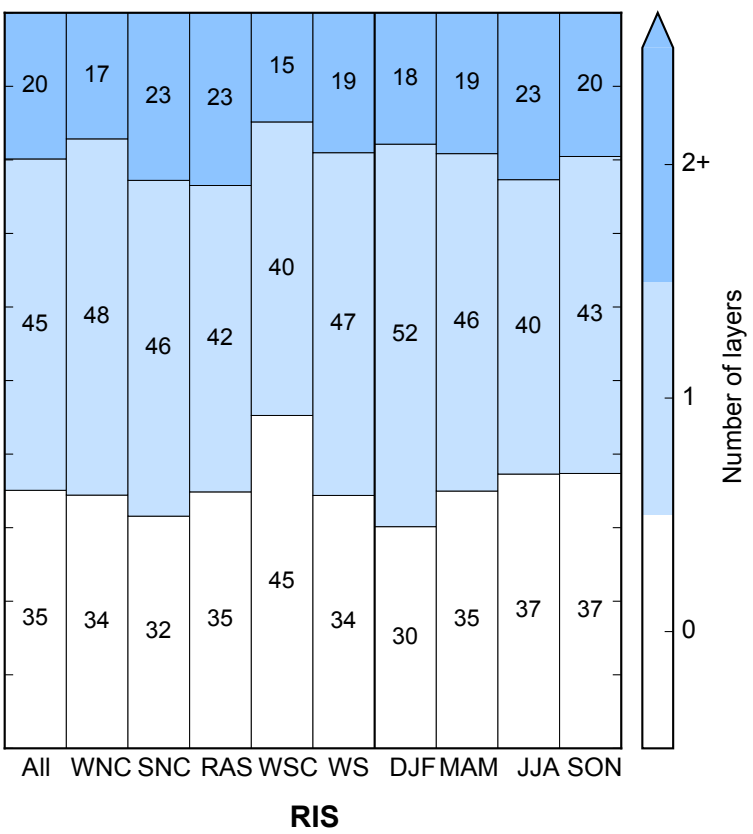

Figure 6. Distribution of the number of cloud layers over the Ross Sea and RIS for all cases, the Coggins regimes and season.

from $17 \%$ in summer to $12 \%$ in winter. Thus, it seems that the occurrence of this class is more associated with periods of weak synoptic forcing; note that these conditions occur more often in summer (see Table 2), which in turn might suggest that local factors are important. Inclusion of information on clear sky rates does not change this result.

Figure $7 \mathrm{~b}$ displays cloud type fractional frequency information for the RIS region. Over the RIS, the As cloud type is most prevalent, varying between 38 and $46 \%$ based on synoptic regime and 25 and $43 \%$ based on season. However, when clear sky occurrence is considered these values reduce to 24 to $32 \%$ for the regimes and 25 to $27 \%$ for the seasons. This suggests that the quantity of altostratus remains nearly constant seasonally. The highest occurrence of the As type when clear skies are taken into consideration is linked to the SNC and RAS regimes, with very similar low occurrences (24 to $25 \%$ ) for the other regimes.

The next most prevalent cloud type over the RIS is the DC type, which changes between occurrence rates of 23 and $33 \%$ for the various Coggins regimes and 24 and $30 \%$ based on seasons. The highest fractional occurrence of the DC type occurs for the RAS regime and the minimum is, surprisingly, linked to the SNC type. Thus, two regimes which are related to strong synoptic forcing in the region have very different impacts on this cloud type. This latter result might be explained by the position of the cyclonic centres, preferentially in the north-eastern Ross Sea for the SNC type, relative to the RIS. When the frequency of clear skies is included in our analysis, a larger variation in this cloud type is linked to synoptic forcing than seasonal changes.
The combined St and Sc cloud types also have an appreciable occurrence rate over the RIS (13\%). When the Coggins regimes are considered this type has a minimum occurrence of $7 \%$ linked to the RAS regime and a maximum occurrence of $20 \%$ linked to the WNC regime. It should be noted that there is an obvious change in the fractional frequency of this type between strong synoptic forcing regimes (RAS and SNC) and weaker synoptic forcing regimes (WNC, WSC, and WS). This separation again suggests that these clouds are linked to periods of weak synoptic forcing. The range of the fractional occurrence rates associated with the different seasons is again smaller than that associated with the synoptic types; summer displays the highest occurrence rate. When clear sky frequencies are included in calculations this result is unchanged.

The fraction of the cirrus ( $\mathrm{Ci}$ ) cloud type is also appreciable over the RIS and has the same frequency of fractional occurrence as the combined St and Sc cloud type (13\%). The fraction of this cloud type maximizes at $17 \%$ for the SNC regime and has a minimum occurrence of $9 \%$ for the WNC regime. The $\mathrm{Ci}$ type is observed most frequently in winter $(20 \%)$ and least in summer $(6 \%)$. Thus, synoptic variations do not appear to be a very strong control on this cloud type. This conclusion is unchanged when the occurrence of clear skies is included in our analysis. We note that the larger fractional occurrence of $\mathrm{Ci}$ over the RIS compared to the Ross Sea could be associated with the proximity of the TAM to the RIS and the influence of isolated cirrus generated by orographically forced waves, this conjecture being supported by Haynes et al. (2011) and Scott and Lubin (2016). 
(a)

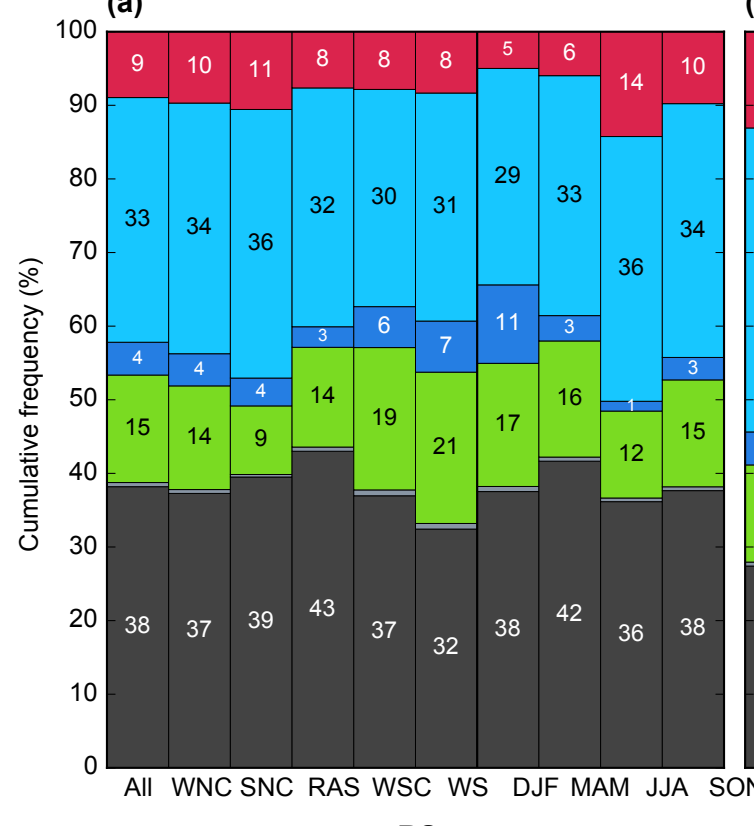

(b)

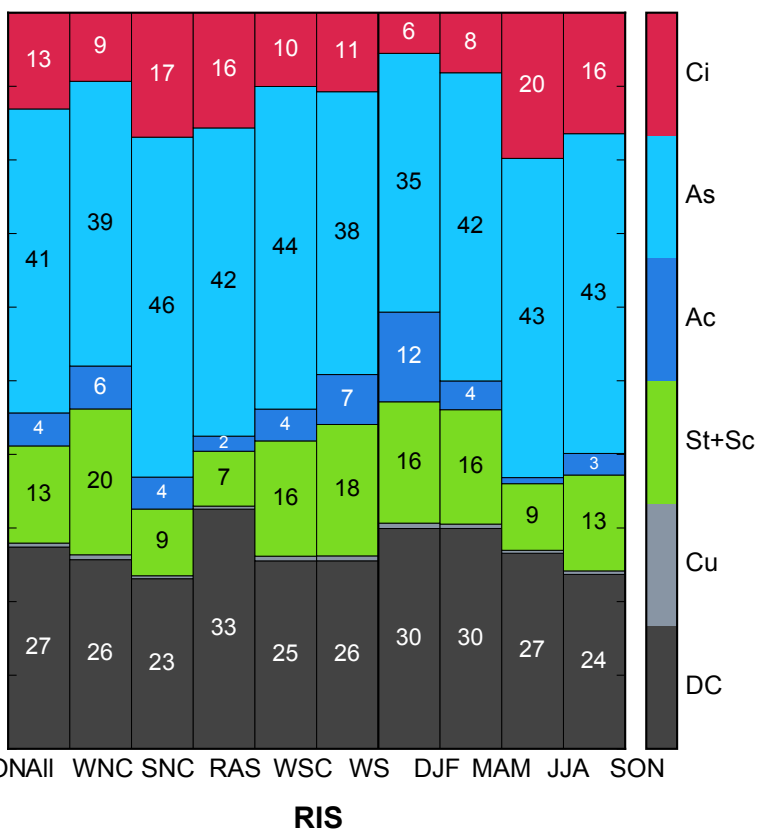

Figure 7. Percent fraction of cloud types over the Ross Sea and RIS for all cases, the Coggins regimes and seasons. The cloud types are identified in Table 1.

\subsection{Cloud height and thickness}

Figure $8 \mathrm{a}$ and $\mathrm{f}$ display joint histograms of the cloud top height vs. the geometric cloud thickness over the Ross Sea and RIS respectively. Figure 8a shows that low-level (below $2 \mathrm{~km}$ a.s.1.) thin cloud (thicknesses below $3 \mathrm{~km}$ ) has a high occurrence over the Ross Sea, an observation previously identified by Adhikari et al. (2012). However, thin clouds are observed relatively frequently for cloud top heights between the surface and approximately $8 \mathrm{~km}$ over the Ross Sea. Clouds that effectively cover nearly the complete vertical column to cloud top (i.e. that have similar thicknesses to their cloud top height) are also observed frequently. We also note that clouds with high cloud tops (above $6 \mathrm{~km}$ ) are relatively rare. The logarithmic scale associated with Fig. 8 highlights that thin low-level cloud is very common. A similar pattern is observed over the RIS region overall (see Fig. 8f), though cloud occurrence is higher in general for the Ross Sea, particularly at lower levels. This is to be expected, given the differences in solar heating of the surface, sea ice concentration changes and sea surface temperatures. In particular, the greater availability of moisture over the Ross Sea associated with open water in summer would likely be an important contributor. The overall pattern is similar to the joint histograms identified by Haynes et al. (2011) over the Southern Ocean.

To further understand the distribution of clouds over the two regions, Fig. $8 \mathrm{~b}-\mathrm{e}$ and $\mathrm{g}-\mathrm{j}$ display anomalies from the annual means for each season for the Ross Sea and RIS respectively. Examination of Fig. 8b-e suggests that the anomaly patterns are rather similar in the summer and autumn, with higher cloud occurrence observed for low-level (below $2 \mathrm{~km}$ ) and mid-level (2 to $6 \mathrm{~km}$ ) cloud which covers the majority of the vertical column up to the cloud top height. Lower cloud occurrence is associated with thin high top clouds for summer and autumn. The anomaly patterns in winter and spring are near mirror images of those in summer and autumn, with higher cloud occurrence for thin high top cloud and lower occurrence (relative to the annual mean) for low-level and mid-level cloud covering the vertical column. High top clouds (above $8 \mathrm{~km}$ ) with a range of thicknesses are also enhanced in winter and spring, with the enhancement being more noticeable for thick clouds in winter. Haynes et al. (2011) previously identified that the increase in thicker clouds in winter over the Southern Ocean may be associated with storm track activity. Haynes et al. (2011) also suggest that the maximum cloud height might vary seasonally based on the tropopause height; therefore, this also seems like a reasonable explanation for the enhanced occurrence of high-level cloud above $8 \mathrm{~km}$ in the winter relative to the summer. The anomaly patterns for each season are generally rather similar over the Ross Sea and the RIS. This is surprising since this may imply that moisture availability is not a large driver of cloud.

Figure $9 b-f$ and $h-1$ display the anomalies from the mean associated with the Coggins regimes for the Ross Sea and RIS respectively. Figure 9a and g display histograms of the frequency of occurrence as a function of thickness and cloud top height for the Ross Sea and RIS respectively, are ex- 


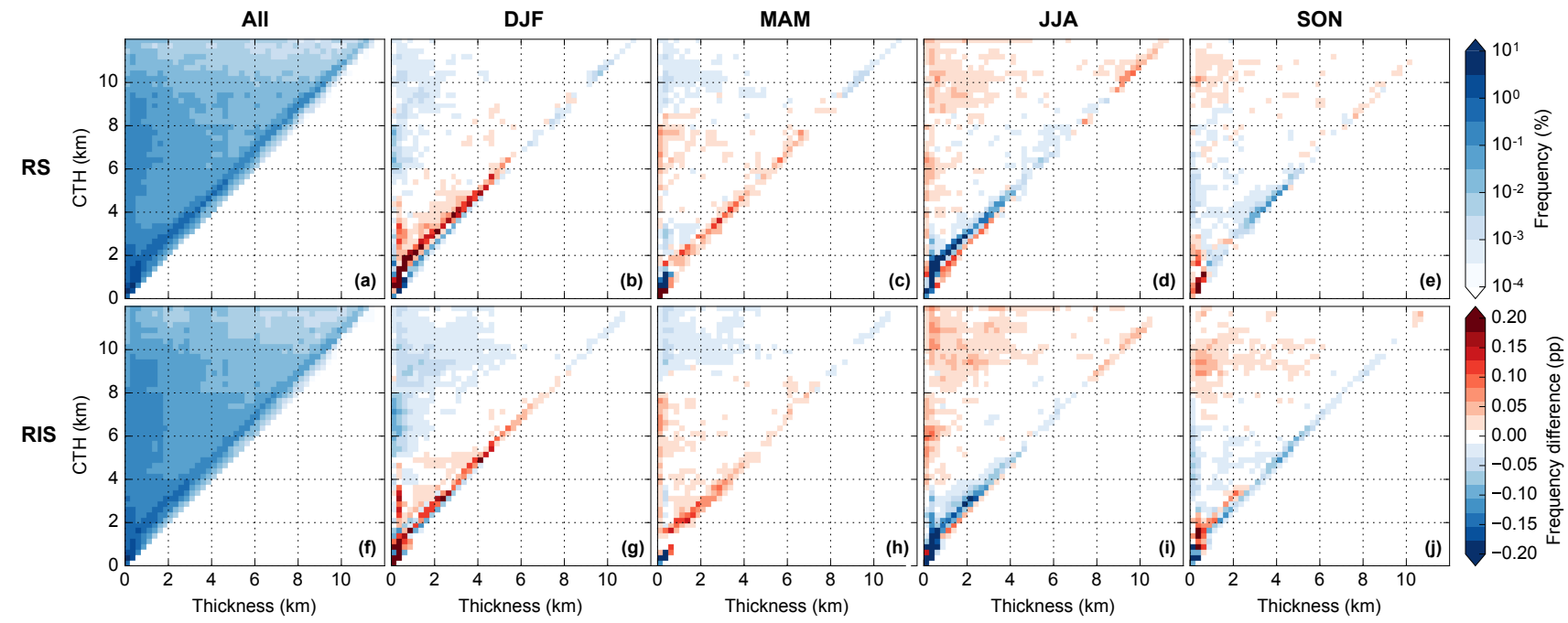

Figure 8. Joint histogram of the cloud top height vs. geometric cloud thickness over the Ross Sea and RIS for the entire year on a logarithmic scale (a,f) and the difference from the annual mean over the respective region (RS and RIS) for each season on a linear scale (b-e, $\mathbf{g}-\mathbf{j}$ ).

act reproductions of Fig. 8a and $\mathrm{f}$ and are included to aid in interpretation. Inspection of the anomalies from the mean linked to different synoptic regimes shows some interesting structures. The SNC regime is linked to a dearth of low-level cloud relative to the mean, particularly over the Ross Sea, while the WSC regime is linked to a considerable enhancement in the frequency of low- and mid-level cloud which covers the majority of the vertical column up to the cloud top height. These variations may also explain the small quantity of multi-layer cloud in this regime over the Ross Sea. The enhancement in the WSC regime is also observed in the WS regime, but that regime is also related to a stronger reduction in clouds covering the vertical column above $4 \mathrm{~km}$. For the SNC regime, the dearth in low-level cloud over the Ross Sea is counter-balanced by an increase in thick (greater than $7 \mathrm{~km}$ deep) high-level cloud relative to the mean, which also accounts for the increased cumulative cloud occurrence for the SNC regime identified in Figs. 5b and 6a. While some aspects of the anomaly for the RAS regime (see Fig. 9d) are similar to the SNC regime pattern (see Fig. 9c), notably a reduction in low-level cloud relative to the mean, differences can be observed. For example, the clouds with high cloud tops (above $8 \mathrm{kma.s.1.}$ ) are under- rather than overrepresented relative to the mean for the entire thickness range for RAS compared to SNC. Enhanced cloud occurrence in the RAS regime is primarily limited to mid-level clouds, most notably linked to clouds with thicknesses below $2 \mathrm{~km}$ and the region identifying that the cloud covers nearly the full atmospheric column.

To put the anomaly patterns identified for the Ross Sea into context, it is also worthwhile considering the patterns over the RIS (Fig. 9h-1). Unlike the seasonal analysis presented in Fig. 8, which displayed large similarities for the anomaly patterns over the Ross Sea and RIS, the patterns show more variability for the WNC, SNC, and RAS regimes between the two regions. In particular, the WNC regime displays a strong enhancement in the quantity of low- and mid-level cloud below $4 \mathrm{kma.s.l}$., with thin cloud and cloud covering the majority of the atmospheric column up to the cloud top height being enhanced. The SNC type shows a similar pattern to that over the Ross Sea, but the strong enhancement of deep, high cloud top height cloud is not observed in this case. The RAS regime joint histogram shows a stronger reduction in low- and mid-level cloud below $4 \mathrm{~km}$ over the RIS than the Ross Sea and the enhanced cloud occurrence region now occurs for high-level cloud (cloud top height above $6 \mathrm{~km}$ a.s.l.). Thus, the vertical extent of the RAS regime changes considerably between the Ross Sea and the RIS. Based on previous work detailed in Steinhoff et al. (2009) this may be associated with vertical ascent over the RIS.

\section{Conclusions and discussion}

This study has quantified the vertical distribution of cloud fraction, phase, and type over the Ross Ice Shelf and southern Ross Sea using 4 years of data from the 2B-CLDCLASSLIDAR R04 product (Sassen et al., 2008) composited using seasons and synoptic regimes (Coggins and McDonald, 2015). The following results highlight the usefulness of incorporating a synoptic classification scheme into the climatological analysis of clouds in this region.

- Large differences exist between the cloud occurrence as a function of altitude for synoptic regimes relative to those for seasonal variation (cf. Figs. 4 and 5). 


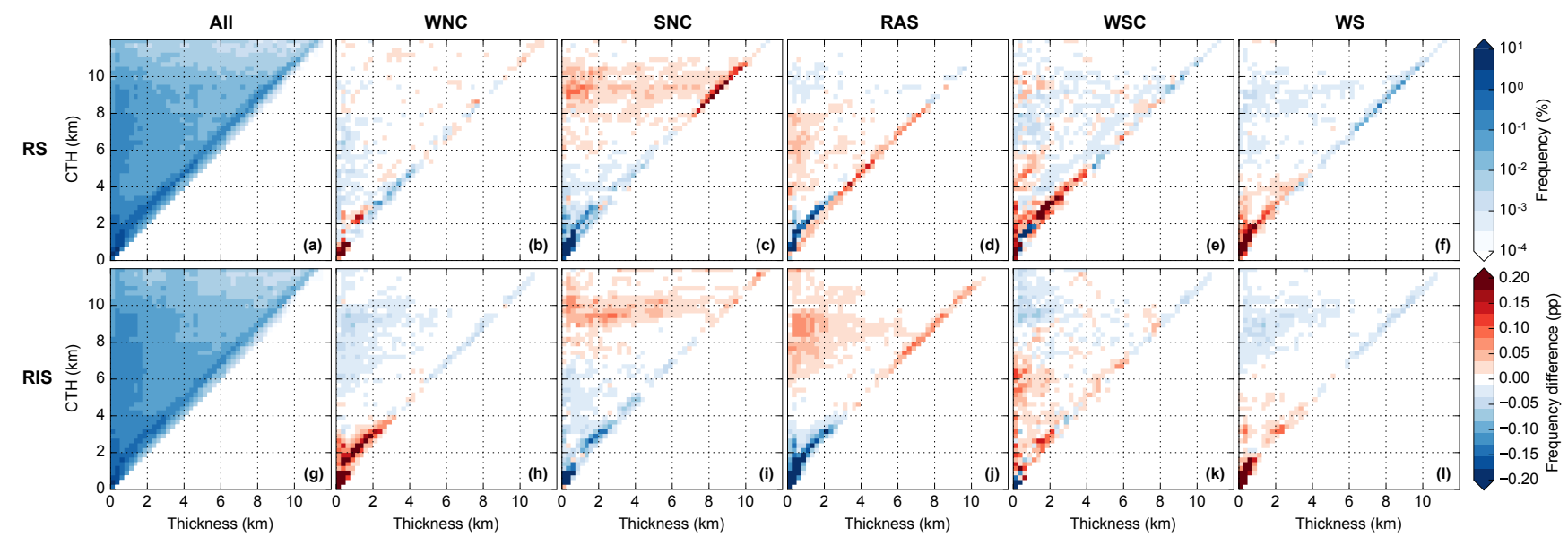

Figure 9. Joint histogram of the cloud top height vs. geometric cloud thickness over the Ross Sea and RIS for the entire year on a logarithmic scale (a,f) and the difference from the annual mean over the respective region (RS and RIS) for each Coggins regime on a linear scale (b-e, g-j).

- There is strong variation in clear sky and multi-layer cloud occurrence as a function of synoptic regime as opposed to season (see Fig. 6).

- There is higher variance in all cloud type occurrences, apart from the cirrus type, over both the Ross Sea and RIS associated with synoptic type compared to seasonal composites (see Fig. 7), which remains true when the frequency of clear skies is taken into account or discounted from our analysis.

- Anomalies from the mean joint histogram of cloud top height against thickness display significant differences over the Ross Sea and RIS sectors as a function of synoptic regime, but are near identical over these two regions when a seasonal analysis is completed (see Figs. 8 and 9).

- Clouds are observed preferentially in the Ross Sea when strong cyclonic centres are observed in the northern Ross Sea.

- The cumulative cloud occurrence observed in the western and eastern portions of the Ross Sea and RIS display larger differences for composites based on the synoptic regimes than seasons. This again suggests a significant influence of the position of cyclonic centres. However, the lack of longitudinal variation associated with the RAS which is traditionally linked to flow near the TAM is unexpected.

We have therefore proven that an analysis based on synoptic regimes explains more of the variation in overall cloud occurrence and specific cloud types than a simple seasonal analysis. This complements previous studies which have inferred these relationships (Verlinden et al., 2011; Adhikari et al., 2012) or used a case study approach (Steinhoff et al.,
2009; Scott and Lubin, 2014). It is however important that the seasonal component of this analysis is not disregarded; it can more effectively capture variations in temperature and subsequently moisture availability via both the water holding capacity of the air and the presence/absence of open ocean due to seasonal sea ice. For example, seasonal analysis identified that the occurrence of mixed phase and liquid water cloud varies more strongly as a function of season than regime, suggesting seasonal variability in mean temperature is a strong driver of ice cloud as previously identified by Haynes et al. (2011).

We also examined the 2BGL4 and 2BGL5 data products. The 2BGL4, used in previous studies in this region, displays a discontinuity at $8.2 \mathrm{~km}$ which is not observable in the other products and appears to correspond to a change in the horizontal and vertical resolutions of the CALIPSO dataset used above this level (Mace et al., 2009). This discontinuity appears to occur at latitudes poleward of $75^{\circ}$ in both hemispheres. The $2 \mathrm{BGL} 5$ product appears to have addressed this issue.

Figures 4 and 5 identify that cloud occurrence as a function of altitude is dominated by low-level cloud, peak cloud occurrence occurring below $2 \mathrm{~km}$ in every season and synoptic regime. This supports previous work by Haynes et al. (2011) and Adhikari et al. (2012) which indicated that there is a relatively high occurrence of low-level cloud above the Southern Ocean and Antarctica respectively. Adhikari et al. (2012) also suggested that low-level cloud constitutes the major cloud type in Antarctica and is more frequent during summer than winter. Our analysis also suggests that stratus and stratocumulus are more common in summer than winter (see Fig. 7) over both the Ross Sea and RIS. Separation into different synoptic classes also implies that periods of weak synoptic forcing (WNC, WSC, and WS Coggins regimes) are important for the formation of these clouds. The greater 
prevalence of these types over the Ross Sea and RIS also suggests that sea ice state and temperature could be important factors.

Adhikari et al. (2012) also identified that high-level and deep clouds are more frequent in winter and spring than summer. The deep convective (DC) cloud type is observed to have a maximum in winter and spring and lowest occurrence rates in summer consistent with the result indicated in Adhikari et al. (2012). However, examination of the variations in the frequency of this cloud type with synoptic regime also suggest that this is most often observed during periods linked to strong cyclonic activity (the SNC regime) as hypothesized by Adhikari et al. (2012). Our synoptic classification additionally identifies that the cloud fraction appears to largely be controlled by the SNC regime which is linked to strong cyclones in the northern Ross Sea; however, RAS events also seem to be a strong controlling factor during winter over the RIS.

The results of this synoptic classification also strongly support the representative nature of the case studies detailed in Scott and Lubin (2014) which identified significantly contrasting cloud properties above Ross Island associated with different meteorological regimes. For example, they identified that warm, moist air moving directly over Ross Island from the north brought low clouds which were likely predominantly liquid phase. Our analysis shows that there is far more liquid water cloud (and also mixed phase cloud) over the Ross Sea than the RIS in every season and for every synoptic type. Thus, any southward flow is likely to have this impact.

In contrast, clouds within marine air masses arriving from the WAIS, and descending onto the Ross Ice Shelf before reaching Ross Island, show strong ice phase signatures based on the study of Scott and Lubin (2014). Our analysis also shows that the RAS regime displays large quantities of ice cloud at all levels over the RIS. The SNC regime is also predominately linked to ice clouds at all levels down to about $2 \mathrm{~km}$ a.s.l. The fact that the SNC and RAS regimes were dominated by ice phase cloud is likely associated with the strong vertical motions linked to these synoptic types. This result is inferred from the discussion in Scott and Lubin (2016) which identified that cloud ice water content is strongly impacted by vertical motion.

The highest cloud occurrence was found over the eastern Ross Sea quadrant during the summer, while the lowest cloud occurrence is observed over the western halves of both the RIS and Ross Sea sectors during the winter. We observe a link between strong synoptic forcing (as judged by wind speeds over the RIS and Ross Sea) and greater occurrence of high-level cloud (above $6 \mathrm{~km}$ a.s.l.), while regimes linked to reduced synoptic forcing seem to be related to a greater occurrence of low-level cloud.

The strong changes in cloud occurrence vertical distribution, cloud fraction and cloud type associated with specific synoptic types allows us to make some wider inferences based on analysis of the Coggins regimes. For example, Coggins and McDonald (2015) demonstrated that the depth and location of the Amundsen Sea Low have significant impacts over the Ross Sea and RIS. Thus, we can infer that changes in the depth of the Amundsen Sea Low will likely have caused significant changes in the cloud environment over the Ross Sea and RIS. The variability in cloud types for different synoptic conditions and the importance of some types for precipitation also suggest that changes in synoptic forcing over the region related to the Amundsen Sea Low may well have impacted snow accumulation in the region. In particular, the high frequency of occurrence of the DC cloud type, a type linked to intense precipitation events statistically (see Table 1), during the RAS regime suggests that snow accumulation in this region may be strongly modulated by the occurrence rate of this synoptic regime. This will be an area of further work.

Data availability. 2B-GEOPROF-LIDAR (2BGL4/5) (Mace et al., 2009; Mace and Zhang, 2014) and 2B-CLDCLASS-LIDAR (2BCL4) (Wang et al., 2012) data are available from the CloudSat Data Processing Center (http://www.cloudsat.cira.colostate.edu, last access: 13 June 2018) or via their FTP site (ftp://ftp.cloudsat. cira.colostate.edu, last access: 13 June 2018). A website account is required for access.

Competing interests. The authors declare that they have no conflict of interest.

Acknowledgements. The authors acknowledge the ECMWF for the ERA-Interim dataset. The CloudSat/CALIPSO data were obtained from the CloudSat Data Processing Center. The SCAR Antarctic Digital Database was obtained from the British Antarctic Survey Geodata Portal. We would also like to acknowledge the financial support that made this work possible provided by the Deep South National Science Challenge via the "Clouds and Aerosols" project and NZARI RFP 2014-2 "Vulnerability of the Ross Ice Shelf in a Warming World".

Edited by: Bernhard Mayer

Reviewed by: three anonymous referees

\section{References}

Adhikari, L., Wang, Z. E., and Deng, M.: Seasonal variations of Antarctic clouds observed by CloudSat and CALIPSO satellites, J. Geophys. Res.-Atmos., 117, 17, https://doi.org/10.1029/2011jd016719, 2012.

Alexander, S. P., Klekociuk, A. R., Pitts, M. C., McDonald, A. J., and Arevalo-Torres, A.: The effect of orographic gravity waves on Antarctic polar stratospheric cloud occurrence and composition, J. Geophys. Res.-Atmos., 116, D060109, https://doi.org/10.1029/2010jd015184, 2011. 
Alexander, S. P., Klekociuk, A. R., McDonald, A. J., and Pitts, M. C.: Quantifying the role of orographic gravity waves on polar stratospheric cloud occurrence in the Antarctic and the Arctic, J. Geophys. Res.-Atmos., 118, 15, https://doi.org/10.1002/2013jd020122, 2013.

Bromwich, D. H., Nicolas, J. P., Hines, K. M., Kay, J. E., Key, E. L., Lazzara, M. A., Lubin, D., McFarquhar, G. M., Gorodetskaya, I. V., Grosvenor, D. P., Lachlan-Cope, T., and van Lipzig, N. P. M.: Tropospheric clouds in Antarctica, Rev. Geophys., 50, 40, https://doi.org/10.1029/2011rg000363, 2012.

Chen, T., Rossow, W. B., and Zhang, Y.: Radiative Effects of Cloud-Type Variations, J. Climate, $13, \quad 264-286$, https://doi.org/10.1175/15200442(2000)013<0264:reoctv>2.0.co;2, 2000.

Chubb, T. H., Jensen, J. B., Siems, S. T., and Manton, M. J.: In situ observations of supercooled liquid clouds over the Southern Ocean during the HIAPER Pole-to-Pole Observation campaigns, Geophys. Res. Lett., 40, 5280-5285, https://doi.org/10.1002/grl.50986, 2013.

CloudSat Data Processing Center: CloudSat Algorithm Uncertainty Synthesis, CloudSat Data Processing Center at Colorado State University, Fort Collins, available at: http://www.cloudsat.cira.colostate.edu/sites/default/files/news/ CloudSat_Algorithm_Uncertainties_Synthesis.pdf (last access: 13 June 2018), 2016.

Coggins, J. H. J. and McDonald, A. J.: The influence of the Amundsen Sea Low on the winds in the Ross Sea and surroundings: Insights from a synoptic climatology, J. Geophys. Res.-Atmos., 120, 2167-2189, https://doi.org/10.1002/2014jd022830, 2015.

Coggins, J. H. J., McDonald, A. J., and Jolly, B.: Synoptic climatology of the Ross Ice Shelf and Ross Sea region of Antarctica: $k$-means clustering and validation, Int. J. Climatol., 34, 23302348, https://doi.org/10.1002/joc.3842, 2014.

Dee, D. P., Uppala, S. M., Simmons, A. J., Berrisford, P., Poli, P., Kobayashi, S., Andrae, U., Balmaseda, M. A., Balsamo, G., Bauer, P., Bechtold, P., Beljaars, A. C. M., van de Berg, L., Bidlot, J., Bormann, N., Delsol, C., Dragani, R., Fuentes, M., Geer, A. J., Haimberger, L., Healy, S. B., Hersbach, H., Holm, E. V., Isaksen, L., Kallberg, P., Kohler, M., Matricardi, M., McNally, A. P., Monge-Sanz, B. M., Morcrette, J. J., Park, B. K., Peubey, C., de Rosnay, P., Tavolato, C., Thepaut, J. N., and Vitart, F.: The ERA-Interim reanalysis: configuration and performance of the data assimilation system, Q. J. Roy. Meteor. Soc., 137, 553-597, https://doi.org/10.1002/qj.828, 2011.

Fogt, R. L. and Bromwich, D. H.: Atmospheric Moisture and Cloud Cover Characteristics Forecast by AMPS, Weather Forecast., 23, 914-930, https://doi.org/10.1175/2008waf2006100.1, 2008.

Frey, R. A., Ackerman, S. A., Liu, Y. H., Strabala, K. I., Zhang, H., Key, J. R., and Wang, X. G.: Cloud detection with MODIS. Part I: Improvements in the MODIS cloud mask for collection 5, J. Atmos. Ocean. Tech., 25, 1057-1072, https://doi.org/10.1175/2008jtecha1052.1, 2008.

Haynes, J. M., Jakob, C., Rossow, W. B., Tselioudis, G., and Brown, J.: Major Characteristics of Southern Ocean Cloud Regimes and Their Effects on the Energy Budget, J. Climate, 24, 5061-5080, https://doi.org/10.1175/2011jcli4052.1, 2011.

Hoskins, B. J. and Hodges, K. I.: A new perspective on Southern Hemisphere storm tracks, J. Climate, 18, 4108-4129, https://doi.org/10.1175/jcli3570.1, 2005.
Lachlan-Cope, T.: Antarctic clouds, Polar Res., 29, 150-158, https://doi.org/10.1111/j.1751-8369.2010.00148.x, 2010.

Lawson, R. P. and Gettelman, A.: Impact of Antarctic mixed-phase clouds on climate, P. Natl. Acad. Sci. USA, 111, 18156-18161, https://doi.org/10.1073/pnas.1418197111, 2014.

Mace, G. G. and Zhang, Q. Q.: The CloudSat radar-lidar geometrical profile product (RL-GeoProf): Updates, improvements, and selected results, J. Geophys. Res.-Atmos., 119, 9441-9462, https://doi.org/10.1002/2013jd021374, 2014.

Mace, G. G., Zhang, Q. Q., Vaughan, M., Marchand, R., Stephens, G., Trepte, C., and Winker, D.: A description of hydrometeor layer occurrence statistics derived from the first year of merged Cloudsat and CALIPSO data, J. Geophys. Res.Atmos., 114, 17, https://doi.org/10.1029/2007jd009755, 2009.

McDonald, A. J., Cassano, J. J., Jolly, B., Parsons, S., and Schuddeboom, A.: An automated satellite cloud classification scheme using self-organizing maps: Alternative ISCCP weather states, J. Geophys. Res.-Atmos., 121, 13009-13030, https://doi.org/10.1002/2016JD025199, 2016.

Nicolas, J. P. and Bromwich, D. H.: Climate of West Antarctica and Influence of Marine Air Intrusions, J. Climate, 24, 49-67, https://doi.org/10.1175/2010jcli3522.1, 2011.

Oreopoulos, L., Cho, N., Lee, D., and Kato, S.: Radiative effects of global MODIS cloud regimes, J. Geophys. Res.-Atmos., 121, 2299-2317, https://doi.org/10.1002/2015jd024502, 2016.

Parish, T. R. and Bromwich, D. H.: Continental-scale simulation of the Antarctic katabatic wind regime, J. Climate, 4, 135-146, https://doi.org/10.1175/15200442(1991)004<0135:cssota>2.0.co;2, 1991.

Parish, T. R. and Bromwich, D. H.: Reexamination of the near-surface airflow over the Antarctic continent and implications on atmospheric circulations at high southern latitudes, Mon. Weather Rev., 135, 1961-1973, https://doi.org/10.1175/mwr3374.1, 2007.

Parish, T. R., Cassano, J. J., and Seefeldt, M. W.: Characteristics of the Ross Ice Shelf air stream as depicted in Antarctic Mesoscale Prediction System simulations, J. Geophys. Res.-Atmos., 111, D12109, https://doi.org/10.1029/2005jd006185, 2006.

Rossow, W. B. and Schiffer, R. A.: Advances in understanding clouds from ISCCP, B. Am. Meteorol. Soc., $\quad 80, \quad 2261-2287, \quad$ https://doi.org/10.1175/15200477(1999)080<2261:aiucfi>2.0.co;2, 1999.

Sassen, K., Wang, Z., and Liu, D.: Global distribution of cirrus clouds from CloudSat/Cloud-Aerosol Lidar and Infrared Pathfinder Satellite Observations (CALIPSO) measurements, J. Geophys. Res.-Atmos., 113, 12, https://doi.org/10.1029/2008jd009972, 2008.

Scott, R. C. and Lubin, D.: Mixed-phase cloud radiative properties over Ross Island, Antarctica: The influence of various synopticscale atmospheric circulation regimes, J. Geophys. Res.-Atmos., 119, 6702-6723, https://doi.org/10.1002/2013jd021132, 2014.

Scott, R. C. and Lubin, D.: Unique manifestations of mixedphase cloud microphysics over Ross Island and the Ross Ice Shelf, Antarctica, Geophys. Res. Lett., 43, 2936-2945, https://doi.org/10.1002/2015g1067246, 2016.

Steinhoff, D. F., Chaudhuri, S., and Bromwich, D. H.: A Case Study of a Ross Ice Shelf Airstream Event: A New Perspective, Mon. Weather Rev., 137, 4030-4046, https://doi.org/10.1175/2009mwr2880.1, 2009. 
Stephens, G. L., Vane, D. G., Tanelli, S., Im, E., Durden, S., Rokey, M., Reinke, D., Partain, P., Mace, G. G., Austin, R., L'Ecuyer, T., Haynes, J., Lebsock, M., Suzuki, K., Waliser, D., Wu, D., Kay, J., Gettelman, A., Wang, Z., and Marchand, R.: CloudSat mission: Performance and early science after the first year of operation, J. Geophys. Res.-Atmos., 113, 18, https://doi.org/10.1029/2008jd009982, 2008.

Tselioudis, G., Rossow, W., Zhang, Y. C., and Konsta, D.: Global Weather States and Their Properties from Passive and Active Satellite Cloud Retrievals, J. Climate, 26, 7734-7746, https://doi.org/10.1175/jcli-d-13-00024.1, 2013.

Tsukernik, M. and Lynch, A. H.: Atmospheric Meridional Moisture Flux over the Southern Ocean: A Story of the Amundsen Sea, J. Climate, 26, 8055-8064, https://doi.org/10.1175/jcli-d12-00381.1, 2013.

Verlinden, K. L., Thompson, D. W. J., and Stephens, G. L.: The Three-Dimensional Distribution of Clouds over the Southern Hemisphere High Latitudes, J. Climate, 24, 5799-5811, https://doi.org/10.1175/2011jcli3922.1, 2011.
Wang, Z. and Sassen, K.: Cloud type and macrophysical property retrieval using multiple remote sensors, J. Appl. Meteorol., 40, 1665-1682, https://doi.org/10.1175/15200450(2001)040<1665:ctampr>2.0.co;2, 2001.

Wang, Z., Vane, D., Stephens, G., and Reinke, K.: Level 2 Combined Radar and Lidar Cloud Scenario Classification Product Process Description and Interface Control Document, Jet Propulsion Laboratory California Institute of Technology Pasadena, California, 2012.

Winker, D. M., Vaughan, M. A., Omar, A., Hu, Y. X., Powell, K. A., Liu, Z. Y., Hunt, W. H., and Young, S. A.: Overview of the CALIPSO Mission and CALIOP Data Processing Algorithms, J. Atmos. Ocean. Tech., 26, 2310-2323, https://doi.org/10.1175/2009jtecha1281.1, 2009. 